\title{
SISTEMA DE PLANTIO DE MILHO EM FILEIRAS DUPLAS E SIMPLES EM CONSÓRCIO COM O FEIJOEIRO COMUM ${ }^{1}$
}

\author{
ISRAEL ALEXANDRE PEREIRA FILHO², ANTÔNIO CARLOS DE OLIVEIRA ${ }^{3}$ e JOSÉ CARLOS CRUZ ${ }^{3}$
}

RESUMO - Este trabalho teve por objetivo identificar sistemas de semeadura do milho em fileiras duplas e simples que permitam melhores condições de rendimento ao feijoeiro em cultivo consorciado. Os experimentos foram instalados na área experimental da Embrapa-Centro Nacional de Pesquisa de Milho e Sorgo (CNPMS), nos anos de 1988/89 e 1989/90. As cultivares de milho precoce BR 201, Cargill 606 e CMS 350 foram semeadas em fileiras duplas de $50 \mathrm{~cm}$ com 60.000 e 40.000 plantas por hectare. O espaçamento entre fileiras duplas foi de $150 \mathrm{~cm}$, e de $100 \mathrm{~cm}$ entre as fileiras simples com 40.000 plantas por hectare. A densidade 120.000 plantas por hectare do feijão cultivar Carioca foi constante em todos os sistemas de cultivo. O rendimento do milho não foi influenciado por esses sistemas. A produtividade do feijoeiro foi menor quando consorciado com os milhos Cargill $606 \mathrm{e}$ CMS 350 em fileiras duplas. O híbrido Cargill 606 em fileiras simples proporcionou maiores rendimentos de grãos à leguminosa. O BR 201 foi o milho mais eficiente para o consórcio, por ser, na média, o mais produtivo, e por permitir, em média, maiores rendimentos do feijoeiro. As produtividades de grãos do consórcio variaram de acordo com os sistemas de cultivo e com as condições climáticas.

Termos para indexação: semeadura, Zea mays, Phaseoulus vulgaris, consorciação de cultura, espaçamento, sistemas de cultivo.

\section{CORN AND COMMON BEAN INTERCROPPING-SYSTEM WITH DOUBLE AND SIMPLE CORN ROWS}

\begin{abstract}
The objective of this work was to identify sowing systems that allow the best condition of common bean yield in intercropping with maize sowed in double and single lines. The trials were carried out at Embrapa-Centro Nacional de Pesquisa de Milho e Sorgo (CNPMS), Minas Gerais State, Brazil, in 1988/89 and 1989/90. The maize cultivars BR 201, Cargill 606 and CMS 350 were sowed in double rows with $50 \mathrm{~cm}$ within the pair of double rows, and $150 \mathrm{~cm}$ between the pair of double rows at 40,000 and 60,000 plants per hectare. The check was $100 \mathrm{~cm}$ single row with 40,000 plants per hectare. Planting density of common beans was 120,000 plants per hectare, which was constant in the systems. Differences were not observed for maize yield between planting systems. Common bean yield decreased when intercropped with maize Cargill 606 and CMS 350 in double lines. The hybrid Cargill 606 in single line increased the yield of the legume. The cultivar BR 201 was the most efficient for intercropping because of higher grain yield average and also because it allowed good average yields of common beans. The planting systems and the climate exerted influence on the grain yields.
\end{abstract}

Index terms: sowing, Zea mays, Phaseolus vulgaris, intercropping, spacing, cropping systems.

\section{INTRODUÇÃO}

O plantio de milho em fileiras duplas foi objeto de estudo em pesquisas passadas, em que as cultivares

\footnotetext{
${ }^{1}$ Aceito para publicação em 24 de junho de 1999.

${ }^{2}$ Eng. Agrôn., M.Sc., Embrapa-Centro Nacional de Pesquisa de Milho e Sorgo (CNPMS), Caixa Postal 151, CEP 35701-970 Sete Lagoas, MG. E-mail: israel@cnpms.embrapa.br

${ }^{3}$ Eng. Agrôn., Dr., Embrapa-CNPMS.
}

utilizadas na época eram de ciclo tardio e geralmente de porte alto. Tais estudos não mostraram vantagens para o cultivo do milho no sistema em discussão.

A semeadura do milho em sistemas de fileiras duplas foi tema de estudos de vários autores, tais como, Green \& Harns citados por Magnavaca et al. (1971), os quais verificaram que o milho no sistema de fileiras duplas superou, em média, o método convencional em 23,5\%. Por outro lado, Magnavaca 
et al. (1971) e Ottman \& Welch (1989) não encontraram em seus trabalhos diferenças entre os sistemas de plantio. Ainda Green \& Harns, citados por Magnavaca et al. (1971), sugerem o plantio de uma segunda cultura de valor econômico nos espaços vagos entre as fileiras duplas e, além disso, recomendam que sejam feitos outros estudos como densidade de plantio e espaçamentos.

Os arranjos de plantio consorciados, em especial o do milho com feijão, permitiram uma série de variações que já foram exaustivamente estudadas por Ramalho et al. (1984), Kranz (1989) e Pereira Filho et al. (1991), que mostraram as vantagens e desvantagens de cada sistema. Dentre os arranjos, os mais comumente usados são os do feijão semeado nas entrelinhas e ou na linha do milho em cultivo simultâneo. Entretanto, ficou evidenciado por Oliveira et al. (1983), Cruz et al. (1984) e Reis et al. (1985) que não há diferença entre sistemas quanto à produtividade do feijoeiro, porém há vantagem do semeio do feijoeiro na linha do milho, que permite o plantio e o cultivo mecânico, além do melhor aproveitamento dos nutrientes pela leguminosa.

No consórcio milho e feijão, vários trabalhos foram feitos, objetivando encontrar cultivares de milho que fossem mais apropriadas para esse sistema, isto é, que oferecessem ao feijoeiro melhores condições de desenvolvimento e produtividade de grãos. Trabalhos conduzidos por Pereira Filho (1981), Wijesinha et al. (1982) e Ramalho et al. (1984), envolvendo cultivares de milho de portes diferentes, não apresentaram diferenças de produtividade do feijoeiro quanto à característica porte. Entretanto, Francis et al. (1979) verificaram queda na produtividade do feijoeiro consorciado com milho de porte baixo. Segundo estes autores, tal fato ocorreu principalmente em razão da alta densidade de plantio utilizada e de fatores climáticos envolvidos.

Em relação ao caráter precocidade, segundo Willey (1979), quanto maior a diferença no ciclo das culturas componentes de um sistema, maior é a utilização dos recursos disponíveis e melhor é a eficiência. Trabalhos conduzidos por Ramalho et al. (1984), Cruz et al. (1987) e Pereira Filho et al. (1991), envolvendo cultivares de milho de ciclos e portes diferentes, não verificaram melhoria na eficiência produtiva do feijoeiro em razão das diferenças nas variáveis citadas.
Com relação à prolificidade, esta característica pode beneficiar o feijoeiro, uma vez que o maior número de espigas por planta compensa a produção do milho semeado em menor densidade de plantio. Além disso, as cultivares atuais possuem folhas mais eretas e estreitas, o que favorece o cultivo em espaçamentos mais fechados, e em fileiras duplas, proporcionando à segunda cultura intercalada, no caso o feijoeiro, um melhor aproveitamento da luz solar.

O trabalho teve por objetivo identificar sistemas de semeadura do milho em fileiras duplas e simples que permitam melhores condições de rendimento do feijoeiro em cultivo consorciado.

\section{MATERIAL E MÉTODOS}

Os experimentos foram conduzidos na área experimental da Embrapa-Centro Nacional de Pesquisa de Milho e Sorgo (CNPMS), em Sete Lagoas, MG, nos períodos agrícolas de 1988/89 e 1989/90. O solo utilizado foi o Latossolo Vermelho-Escuro, textura argilosa, fase cerrado. A precipitação média local é de $1.340 \mathrm{~mm}$ e altitude de 732 metros.

Foram utilizadas três cultivares de milho precoce BR 201, CMS 350 e Cargill 606 e a cultivar de feijão Carioca. Os sistemas estudados foram os seguintes: sistemas 1 e 2, em que o milho foi semeado em fileiras duplas com densidades de 40.000 e 60.000 plantas por hectare, respectivamente, e o feijão, semeado nos intervalos entre fileiras duplas. No sistema 3 (tradicional), o milho foi semeado em fileiras simples, com densidade de 40.000 plantas por hectare, e o feijão, semeado na mesma linha do cereal. Em todas as situações, a densidade do feijão foi de 120.000 plantas por hectare. O espaçamento do milho em fileiras duplas foi de $1,50 \mathrm{~m}$, e em fileiras simples, de $1,00 \mathrm{~m}$.

O delineamento experimental foi o de blocos ao acaso, com três repetições. Os tratamentos foram constituídos em fatorial 3 × $3+1$ (três cultivares de milho, três sistemas de plantio, mais o monocultivo do feijão). As parcelas foram constituídas por um conjunto de três fileiras duplas de milho e quatro linhas de feijão semeadas nos espaços destas, com $6 \mathrm{~m}$ de comprimento, sendo colhido como área útil a fileira dupla útil do milho e duas fileiras de feijão situadas ao lado. No sistema de fileiras simples, a parcela foi constituída por quatro linhas de milho com feijão, de $6 \mathrm{~m}$ de comprimento, a espaços de $1 \mathrm{~m}$, nas quais foram colhidas como área útil as duas fileiras centrais de milho com feijão intercalado. Foi desprezado $0,50 \mathrm{~m}$ das extremidades de cada parcela. No monocultivo do feijão, as parcelas com espaçamento de $0,50 \mathrm{~m}$ foram constituídas 
por quatro linhas de $6 \mathrm{~m}$ de comprimento, sendo colhidas como área útil as duas linhas centrais. Utilizaram-se, como adubação de plantio para o milho e feijão consorciados, $300 \mathrm{~kg} \mathrm{ha}^{-1}$ da fórmula 4-30-16+Zn, e, em cobertura, após a emergência das plântulas, $30 \mathrm{~kg} \mathrm{ha}^{-1}$ de $\mathrm{N}$ na forma de sulfato de amônio.

Avaliaram-se somente as produções de milho e feijão corrigidas para a umidade de $13 \%$. Utilizou-se o modelo de análise de variância bivariada, proposto por Pearce \& Gilliver (1978, 1979). Essa técnica, segundo Cruz et al. (1991), propicia a interpretação mais adequada dos resultados, por descrever a superioridade relativa dos tratamentos por meio do rendimento do consórcio, que leva em consideração, simultaneamente, os rendimentos das duas culturas envolvidas no experimento.

Considerou-se, no processo de análise:

$\mathrm{Y}_{\mathrm{mi}}=$ rendimento médio da i-ésima cultivar de milho em consórcio;

$\mathrm{Y}_{\mathrm{f}}=$ rendimento médio da cultivar de feijão em consórcio com a i-ésima cultivar de milho;

$\mathrm{Q}_{11}=$ quadrado médio do resíduo de análise de variância do rendimento de milho em consórcio;

$\mathrm{Q}_{22}=$ quadrado médio do resíduo da análise de variância do rendimento do feijão em consórcio;

$\mathrm{Q}_{12}=$ produto médio do resíduo da análise referente aos rendimentos do milho e do feijão consorciados.

As variáveis originais foram transformadas, com base nas estatísticas anteriores, resultando em novas variáveis não correlacionadas $\mathrm{X}_{\mathrm{mi}} \mathrm{e} \mathrm{X}_{\mathrm{f}}$, onde:

$\mathrm{X}_{\mathrm{mi}}=\mathrm{Y}_{\mathrm{mi}} / \sqrt{\mathrm{Q}_{11}}$, e

$\mathrm{X}_{\mathrm{f}}=\left(\mathrm{Y}_{\mathrm{mi}}-\mathrm{Q}_{12} \mathrm{Y}_{\mathrm{f}}\right) / \sqrt{\mathrm{Q}_{22}-\mathrm{Q}_{12} / \mathrm{Q}_{11}}$.

Pode-se demonstrar que Variância $\left(\mathrm{X}_{\mathrm{mi}}\right)=$ Variância $\left(\mathrm{X}_{\mathrm{f}}\right)=1$ e covariância $\left(\mathrm{X}_{\mathrm{mi}}, \mathrm{X}_{\mathrm{f}}\right)=0$, isto é, as variáveis $\mathrm{X}_{\mathrm{mi}}$ e $X_{f}$ são independentes, podendo ser representadas em eixos perpendiculares.

Visto que $X_{\mathrm{mi}}$ e $\mathrm{X}_{\mathrm{f}}$ não são correlacionadas, e têm a mesma variância, o deslocamento em uma direção é tão importante quanto um deslocamento similar na outra direção.

\section{RESULTADOS E DISCUSSÃO}

Os resultados obtidos pela análise bivariada estão representados nas Figs. 1 a 5, onde as coordenadas são estabelecidas por $\mathrm{X}_{\mathrm{mi}}$ (milho) e $\mathrm{X}_{\mathrm{f}}$ (feijão).

Os rendimentos médios de grãos de milho e feijão consorciados nos diferentes sistemas de semeaduras são apresentados na Tabela 1. Considerando-se as análises univariadas, observou-se que não houve diferenças significativas entre os rendimentos de milho, que possam ser atribuídas aos diferentes sistemas de semeadura. Esses resultados concordam com os obtidos por Magnavaca et al. (1971) e Ottman \& Welch (1989), que também não encontraram diferença de produtividade de grãos de milho nos sistemas de semeadura de fileiras duplas ou simples. Em relação ao rendimento de grãos do feijoeiro, não se detectou diferença significativa entre os sistemas de semeadura no consórcio com o milho BR 201. Esse fato mostra o desempenho da cultivar BR 201, que, além de ter sido, na média, a mais produtiva (4.887 $\left.\mathrm{kg} \mathrm{ha}^{-1}\right)$ e não ser influenciada pelos sistemas de semeadura, permitiu que o feijoeiro não sofresse ação dos sistemas de semeadura, no processo produtivo. No entanto, quando a leguminosa foi consorciada com os milhos CMS 350 e Cargill 606, o rendimento de grãos variou, conforme mostra a Tabela 1 , onde se observa que os sistemas de fileiras duplas e simples com 40.000 plantas por hectare proporcionaram índices de produtividades iguais para feijoeiro. Nos mesmos tratamentos, o sistema de fileiras duplas com 60.000 plantas por hectare contribuiu para reduzir o rendimento de grãos do feijoeiro, exceto quando consorciado com o milho BR 201.

As dispersões gráficas dos escores dos tratamentos (cultivares de milho e sistema de plantio) permitiram mostrar, no primeiro estudo (Fig. 1), que os sistemas de plantio envolvendo as cultivares BR 201 e CMS 350 proporcionaram boas condições de produtividade de milho. O contrário foi observado com a cultivar Cargill 606, cujos sistemas de plantio permitiram melhores condições de rendimento ao feijoeiro, exceto o plantio em fileiras duplas com densidade de 60.000 plantas por hectare, no qual se observaram as menores produtividades de ambas as culturas (Fig. 1).

A Fig. 2 elucida a dispersão gráfica dos escores dos tratamentos no segundo ano agrícola, em que a análise bivariada permitiu exibir discrepância acentuada dos escores dos sistemas em relação aos do primeiro ano de condução do trabalho. A diferença discriminatória se deu com o sistema de plantio 2, envolvendo a cultivar de milho Cargill 606, que, ao contrário do primeiro ano agrícola, proporcionou ao cereal alto índice de produtividade. Este mesmo sistema e ainda o sistema 3, quando envolveram as cultivares de milho BR 201 e CMS 350, mostraram que 
estas possuem boas condições de rendimento. O sistema de plantio 1 proporcionou boas condições de rendimento para o milho e feijão. Entretanto, com as cultivares de milho Cargill 606 e CMS 350 favoreceu mais ao feijoeiro, permitindo-lhe melhores rendimentos.

Na média dos dois anos, a dispersão gráfica dos escores dos tratamentos (Fig. 3) evidencia que a melhor opção para o consórcio é a cultivar BR 201, nos sistemas de plantio 1, 2 e 3, por proporcionar bons rendimentos de milho e de feijão ao mesmo tempo. O sistema de plantio 2, envolvendo as cultivares de milho BR 201, Cargill 606 e CMS 350, foi mais eficiente para o cultivo do milho. Entretanto, os sistemas de plantio 1 e 3 envolvendo as cultivares de milho CMS 350 e Cargill 606, principalmente, foram mais viáveis ao rendimento do feijoeiro.

$\mathrm{Na}$ interpretação das dispersões gráficas dos escores dos tratamentos, que representam as médias conjuntas apenas dos sistemas de plantio, vê-se, na Fig. 4, que o sistema 2 proporcionou maiores rendimentos ao milho, e que o sistema 3 , ou seja, o tradi-

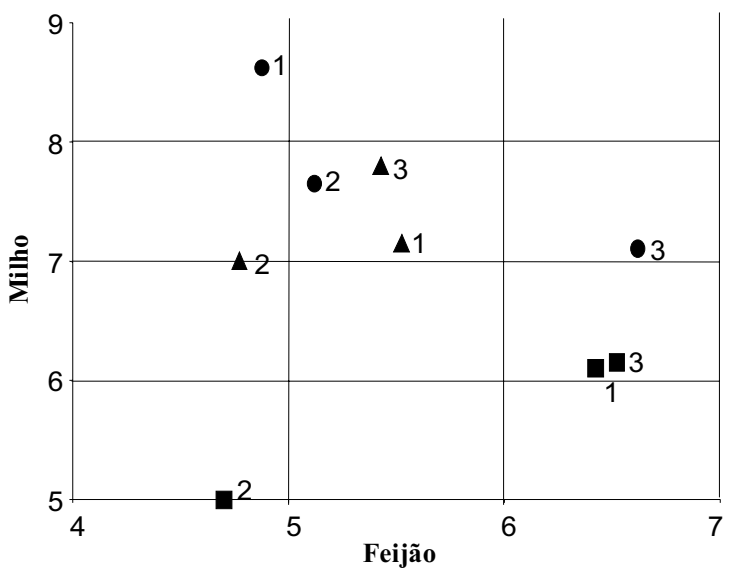

FIG. 1. Dispersão gráfica dos escores (variáveis não condicionadas) de sistemas de plantio no consórcio milho e feijão $(\bullet=$ BR201; $\triangle=$ CMS 350; D = Cargill 606; $1=40.000$ plantas $/$ ha $\mathrm{em}$ fileiras duplas; $2=60.000$ plantas $/ \mathrm{ha}$ em fileiras duplas; $3=\mathbf{4 0 . 0 0 0}$ plantas $/ \mathrm{ha}$ em fileiras simples). Embrapa-CNPMS, Sete Lagoas, MG, 1988/90.

TABELA 1. Rendimentos médios de grãos em $\left(\mathrm{kg} \mathrm{ha}^{-1}\right)$ obtidos pela análise conjunta de três cultivares de milho consorciadas com o feijoeiro em três sistemas de semeadura, e valores das variáveis não correlacionadas, $X_{\mathrm{f}}$ e $X_{\text {mi }}$ Embrapa-CNPMS, Sete Lagoas, MG, 1988/90.

\begin{tabular}{|c|c|c|c|c|c|c|c|c|c|c|c|c|c|}
\hline \multirow[t]{2}{*}{ Cultivar } & \multirow[t]{2}{*}{ Sistema } & \multicolumn{4}{|c|}{ Ano 1} & \multicolumn{4}{|c|}{ Ano 2} & \multicolumn{2}{|c|}{ Média conjunta } & \multirow[t]{2}{*}{$\mathrm{X}_{\mathrm{f}}$} & \multirow[t]{2}{*}{$\overline{\mathrm{X}_{\mathrm{mi}}}$} \\
\hline & & Feijão & $\mathrm{X}_{\mathrm{f}}$ & Milho & $\mathrm{X}_{\mathrm{mi}}$ & Feijão & $\mathrm{X}_{\mathrm{f}}$ & Milho & $\mathrm{X}_{\mathrm{mi}}$ & Feijão & Milho & & \\
\hline \multirow[t]{3}{*}{ BR 201} & FD 40 & 356,0 & 4,89 & $5.596,7$ & 8,58 & 510,0 & 7,26 & $4.500,7$ & 7,35 & $433,0 \mathrm{a}$ & $5.048,7 \mathrm{a}$ & 6,05 & 7,97 \\
\hline & FD 60 & 370,0 & 5,09 & $5.047,0$ & 7,69 & 447,0 & 6,79 & $5.150,0$ & 8,49 & $423,5 \mathrm{a}$ & $5.098,5 \mathrm{a}$ & 5,92 & 8,06 \\
\hline & FS 40 & 482,7 & 6,64 & $4.797,0$ & 7,18 & 410,0 & 5,83 & $4.233,7$ & 6,97 & $446,3 \mathrm{a}$ & $4.515,3 \mathrm{a}$ & 6,24 & 7,08 \\
\hline Média & & & & & & & & & & 434,0 & $4.887,0$ & & \\
\hline \multirow[t]{3}{*}{ CMS 350} & FD 40 & 398,0 & 5,47 & $4.786,0$ & 7,25 & 511,0 & 7,27 & $3.792,7$ & 6,14 & $454,5 \mathrm{a}$ & $4.289,3 \mathrm{a}$ & 6,35 & 6,70 \\
\hline & FD 60 & 349,7 & 4,81 & $4.599,7$ & 7,00 & 364,3 & 5,18 & $4.181,3$ & 6,91 & $357,0 \mathrm{~b}$ & $4.390,5 \mathrm{a}$ & 4,99 & 6,95 \\
\hline & FS 40 & 390,3 & 5,36 & $5.161,0$ & 7,85 & 545,0 & 7,75 & $3.387,0$ & 5,42 & $467,7 \mathrm{a}$ & $4.274,0 \mathrm{a}$ & 6,54 & 6,66 \\
\hline Média & & & & & & & & & & 426,0 & $4.317,0$ & & \\
\hline \multirow[t]{3}{*}{ Cargill 606} & FD 40 & 463,0 & 6,36 & $4.144,0$ & 6,16 & 478,3 & 6,80 & $3.886,7$ & 6,32 & $470,7 \mathrm{ab}$ & $4.015,3 \mathrm{a}$ & 6,58 & 6,23 \\
\hline & FD 60 & 343,7 & 4,72 & $3.422,0$ & 5,12 & 472,3 & 6,72 & $5.700,3$ & 9,44 & $408,0 \mathrm{~b}$ & $4.561,2 \mathrm{a}$ & 5,70 & 7,18 \\
\hline & FS 40 & 472,3 & 6,49 & $4.193,7$ & 6,23 & 595,3 & 8,47 & $3.670,7$ & 5,87 & $533,8 \mathrm{a}$ & $3.932,2 \mathrm{a}$ & 7,46 & 6,04 \\
\hline Média & & & & & & & & & & 470,0 & $4.169,0$ & & \\
\hline QM resíduo & & $5.292,19$ & & $394.627,33$ & & $4.940,65$ & & $40.432,90$ & & 5116,42 & $367.530,12$ & & \\
\hline $\mathrm{Q}_{12}$ & & & $3.258,9$ & & & & $.094,24$ & & & & 76,59 & & \\
\hline
\end{tabular}

${ }^{1} \mathrm{X}_{\mathrm{mi}}=$ rendimento médio da i-ésima cultivar de milho em consórcio; $\mathrm{X}_{\mathrm{f}}=$ rendimento médio da cultivar de feijão em consórcio com a i-ésima cultivar de milho; FD: fileira dupla; FS: fileira simples; $\mathrm{Q}_{12}$ : produto médio do resíduo da análise referente aos rendimentos do milho e do feijão consorciados. 


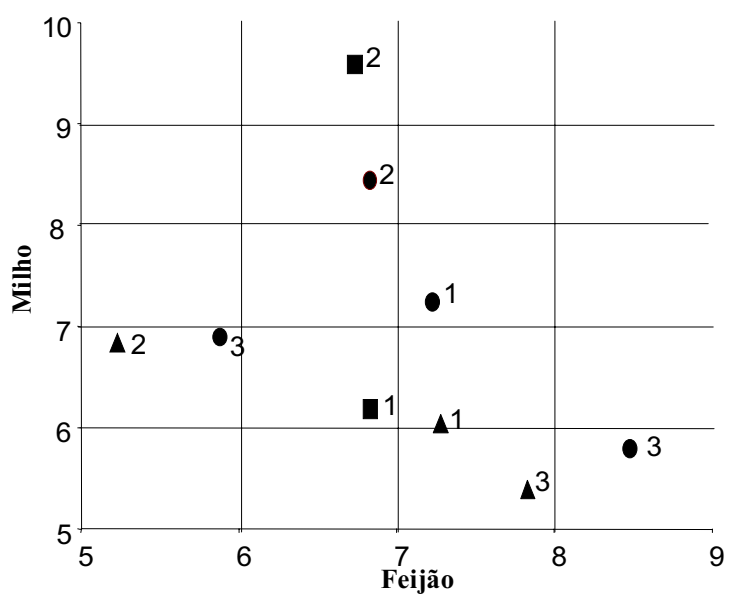

FIG. 2. Dispersão gráfica dos escores (variáveis não condicionadas) de sistemas de plantio no consórcio milho e feijão $(\boldsymbol{\theta}=\mathrm{BR201} \boldsymbol{\Delta}=\mathrm{CMS} 350$; $\square=$ Cargill $606 ; 1=40.000$ plantas $/ \mathrm{ha}$ em fileiras duplas; $2=60.000$ plantas/ha em fileiras duplas; $3=40.000$ plantas $/$ ha em fileiras simples). Embrapa-CNPMS, Sete Lagoas, MG, 1988/90.

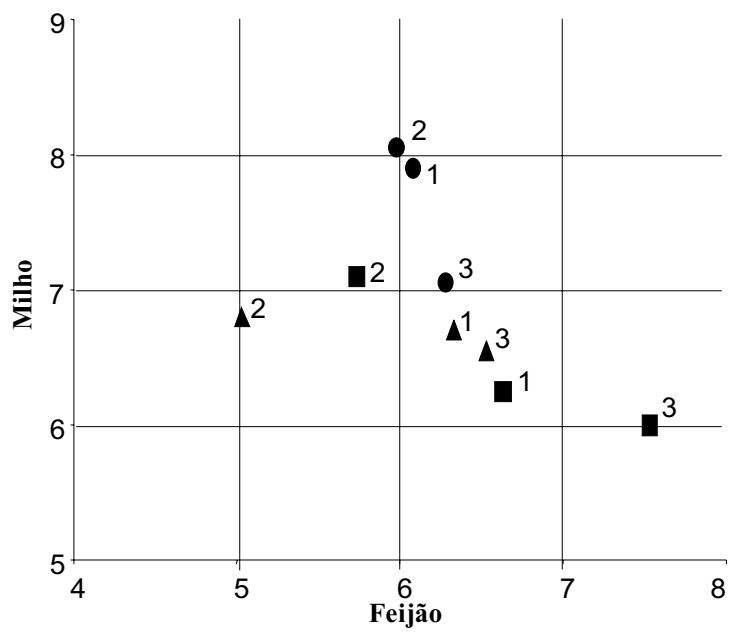

FIG. 3. Dispersão gráfica dos escores (variáveis não condicionadas) de sistemas de plantio no consórcio milho e feijão $(\mathbf{O}=\mathrm{BR201} \boldsymbol{\Delta}=\mathrm{CMS} 350$; $\square=$ Cargill $606 ; 1=40.000$ plantas $/$ ha $\mathrm{em}$ fileiras duplas; $2=60.000$ plantas/ha em fileiras duplas; $3=40.000$ plantas/ha em fileiras simples). Embrapa-CNPMS, Sete Lagoas, MG, 1988/90. cional, permitiu maiores rendimentos ao feijoeiro. $\mathrm{O}$ sistema 1 foi mais vantajoso para o consórcio, porque possibilitou boa produtividade para o milho e para o feijoeiro.

Em relação às cultivares e seus comportamentos diante do consórcio, a análise de variância bivariada possibilitou apontar a cultivar de milho BR 201 como a de melhor desempenho nesta prática de plantio, uma vez que proporcionou altos escores no rendimento de milho e feijão. As cultivares CMS 350 e Cargill 606, principalmente esta última, foram as que propiciaram os melhores rendimentos ao feijoeiro (Fig. 5).

As dispersões gráficas, apontadas pela análise de bivariância dos escores dos tratamentos (cultivares de milho e sistemas de plantio) de ano para ano, tiveram como causa as condições climáticas, principalmente a chuva, como evidencia a Fig. 6. No primeiro ano agrícola (Fig. 1), sobressaíram os sistemas 1 e 3 com as cultivares de milho BR 201 e CMS 350, as quais apresentam plantas com sistema radicular desenvolvido e são bem adaptadas às condições de solo a que foram submetidas, conferindo-se-lhes, assim, melhores condições de crescimento em situações com baixo nível de umidade do solo. Os referi-

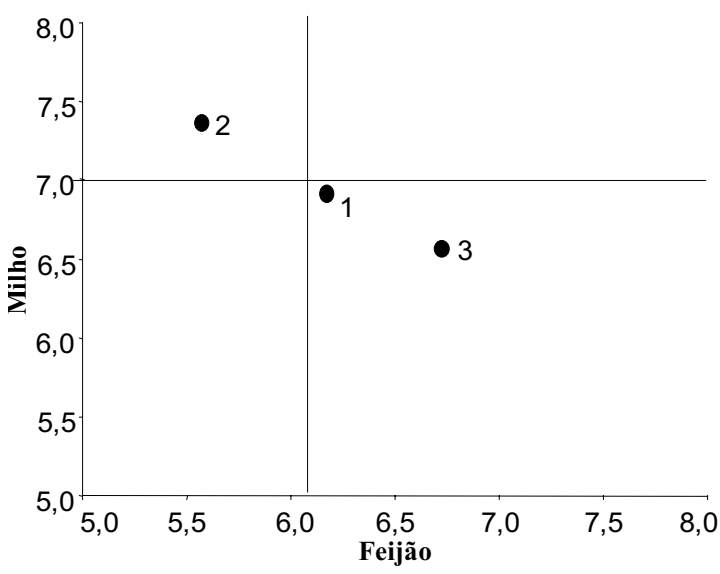

FIG. 4. Dispersão gráfica dos escores de três sistemas de plantio no consórcio milho e feijão $(1=40.000 \mathrm{plantas} / \mathrm{ha} \mathrm{em}$ fileiras duplas; $2=\mathbf{6 0 . 0 0 0}$ plantas $/$ ha em fileiras duplas; $3=40.000$ plantas/ha em fileiras simples). Embrapa-CNPMS, Sete Lagoas, MG, 1988/90.

Pesq. agropec. bras., Brasília, v.35, n.5, p.951-957, maio 2000 
dos sistemas e as citadas cultivares de milho ocuparam posições relativamente próximas no gráfico de dispersão (Fig. 1). Observa-se, de maneira geral, que mesmo o sistema de plantio 2, com 60.000 plantas

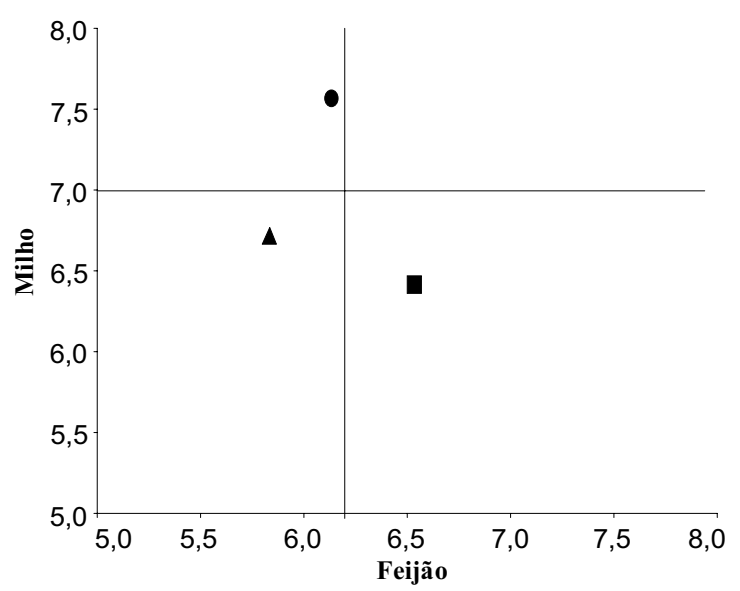

FIG. 5. Dispersão gráfica dos escores de três cultivares de milho em consórcio com o feijoeiro $(\bullet=$ BR201; $\Delta=$ CMS 350; $\boldsymbol{\square}=$ Cargill 606). Embrapa-CNPMS, Sete Lagoas, MG, 1988/90.

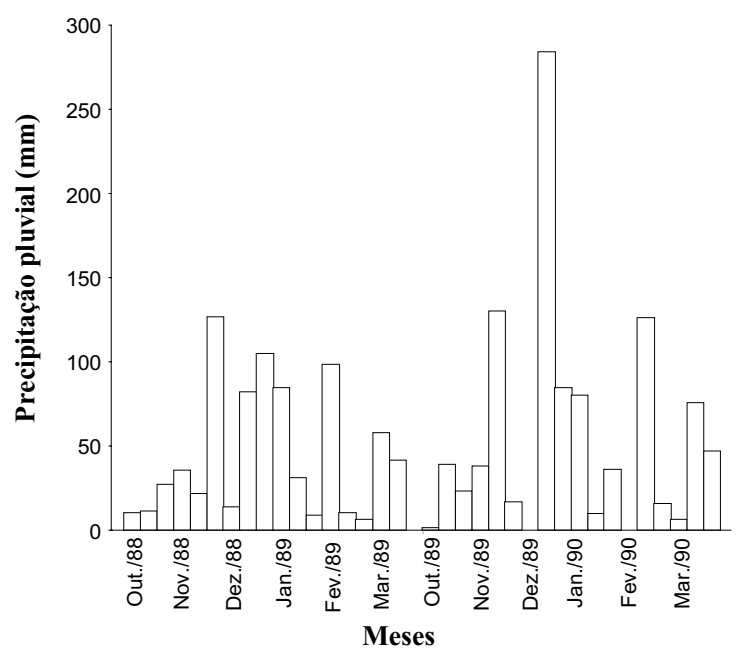

FIG. 6. Precipitação pluvial por período de dez dias, observada na área experimental da EmbrapaCNPMS nos meses de outubro de 1988 a março de 1990. Embrapa-CNPMS, Sete Lagoas, MG. por hectare, envolvendo as cultivares de milho BR 201 e CMS 350, foi mais eficiente em situação pouco favorável de cultivo; já o mesmo sistema utilizando o milho Cargill 606 teve mau desempenho, possivelmente em virtude do baixo índice pluviométrico ocorrido no primeiro ano.

No segundo ano, quando a precipitação pluvial foi mais elevada, a dispersão gráfica dos escores (Fig. 2) dos tratamentos mostrou melhores condições de rendimento no milho, principalmente no sistema 2, ou seja, com a maior densidade. Esta resposta é provavelmente em decorrência de maiores índices pluviométricos ocorridos no período agrícola 1989/90.

O sistema de plantio 1, com a cultivar de milho BR 201, continuou, em relação ao ano anterior, mostrando bons escores de rendimento tanto para milho como para feijão. Assim, pode-se observar que a cultivar de milho BR 201, independentemente do sistema de plantio, mostrou não variar com as oscilações climáticas, pois em situação de pouca ou alta umidade teve bom comportamento produtivo, o que evidencia ser material de boa estabilidade de rendimento em condições adversas (Fig. 5).

Em geral, os sistemas de plantio, independentemente das densidades de plantas, não afetaram o rendimento de grãos do milho (Tabela 1), o que concorda com os resultados obtidos por Magnavaca et al. (1971), Ottman \& Welch (1989) e Pereira Filho et al. (1991), mas está em desacordo com os resultados obtidos por Green \& Harns, citados por Magnavaca et al. (1971), que verificaram melhor rendimento do milho no sistema de fileiras duplas. Quanto ao consórcio, os dados evidenciaram que o sistema de fileiras duplas, com 40.000 plantas por hectare, foi o mais viável, por proporcionar bons rendimentos tanto para o milho como para o feijoeiro. Os resultados apontaram ainda maiores rendimentos do milho no sistema de plantio em fileiras duplas com densidade de 60.000 plantas por hectare, e do feijoeiro, no sistema de plantio em fileiras simples com densidade de 40.000 plantas por hectare.

\section{CONCLUSÕES}

1. O rendimento de grãos do milho não é influenciado pelos sistemas de cultivo. 
2. Obtêm-se os melhores rendimentos de grãos do feijoeiro no sistema de fileiras simples, com 40.000 plantas por hectare.

3. O milho híbrido BR 201 apresenta, na média, a melhor eficiência do consórcio.

4. O milho híbrido Cargill 606, independentemente dos sistemas, proporciona ao feijoeiro melhor rendimento médio de grãos.

\section{REFERÊNCIAS}

CRUZ, J.C.; CORREA, L.A.; RAMALHO, M.A.P.; SILVA, A.F. da; OLIVEIRA, A.C. Avaliação de cultivares de milho associado com o feijão. Pesquisa Agropecuária Brasileira, Brasília, v.19, n.2, p.163168, fev. 1984.

CRUZ, C.D.; MAGALHÃES, P.C.; PEREIRA FILHO, I.A. Análise bivariada do rendimento de milho e feijão em sistema consorciado. Revista Ceres, Viçosa, v.38, n.218, p.332-339, 1991.

CRUZ, J.C.; RAMALHO, M.A.P.; SALLES, L.T.G. de. Utilização de cultivares de milho prolífico no consórcio milho-feijão. Pesquisa Agropecuária Brasileira, v.22, n.2, p.203-211, fev. 1987.

FRANCIS, C.A.; FLOR, C.A.; TEMPLE, S.R. Adapting varieties for intercropped systems in the tropics. In: SYMPOSIUM ON MULTIPLE CROPPING, 1975, Knoxville. Proceedings. Madison : ASA/CSSA/ SSSA, 1979. p.235-253. (ASA. Special Publication, 27).

KRANZ, W.M. População de plantas. In: IAPAR (Londrina, PR). O feijão no Paraná. Londrina, 1989. p.115-125. (IAPAR. Circular, 63).

MAGNAVACA, R.; LOBATO NETO, J.; SILVA, J. Efeito de borda em um híbrido de milho. Pesquisa Agropecuária Brasileira, Brasília, v.6, n.1, p.273278, jan. 1971.

OLIVEIRA, L.A.A. de; GALVÃO, S.D.; FONTES, L.A.N.; CONDE, A.R. Adubação entre sistemas de associação de milho com feijão (Phaseolus vulgaris
L.). Revista Ceres, Viçosa, v.30, n.71, p.375-387, 1983.

OTTMAN, M.J.; WELCH, L.F. Planting patterns and radiation interception, plant nutrient concentration, and yield in corn. Agronomy Journal, Madison, v.81, n.1, p.167-174, 1989.

PEARCE, S.C.; GILLIVER, B. Graphical assessment of intercropping methods. Journal of Agricultural Science, Cambridge, Grã-Bretanha, v.93, n.1, p.5168,1979

PEARCE, S.C.; GILLIVER, B. The statistical analysis of data from intercropping experiment. Journal of Agricultural Science, Cambridge, Grã-Bretanha, v.91, n.3, p.625-632, 1978.

PEREIRA FILHO, I.A. Estudo do consórcio do feijão com milho de diferentes arquiteturas. Maceió : EPEAL, 1981.2p. (EPEAL. Pesquisa em Andamento, 3).

PEREIRA FILHO, I.A.; CRUZ, J.C.; RAMALHO, M.A.P. Produtividade e índice de espiga de três cultivares de milho em sistema de consórcio com o feijão comum. Pesquisa Agropecuária Brasileira, Brasília, v.26, n.5, p.745-751, maio 1991.

RAMALHO, M.A.P.; SILVA, A.F. da; AIDAR, H. Cultivares de milho e feijão em monocultivo e em dois sistemas de consorciação. Pesquisa Agropecuária Brasileira, Brasília, v.19, n.7, p.827-833, jul. 1984.

REIS, W.P.; RAMALHO, M.A.P.; CRUZ, J.C. Arranjos e populações do feijoeiro na consorciação com o mi1ho. Pesquisa Agropecuária Brasileira, Brasília, v.20, n.5, p.575-584, maio 1985.

WIJESINHA, A.; FEDERER, N.T.; CARVALHO, J.R.P.; PORTES, T.A. Some statistical analysis for a maize and beans intercropping experiment. Crop Science, Madison, v.22, n.3, p.660-666, 1982.

WILLEY, R.W. Intercropping - its importance and research needs. Part. 1. Competition and yield advantages. Field Crop Abstracts, Wallingford, v.32, n.1, p.110, Jan. 1979. 